\title{
Interferon-gamma release assays for screening of health care workers in low tuberculosis incidence settings: Dynamic patterns and interpretational challenges
}

\author{
Madhukar Pai MD PhD ${ }^{1,2}$, Kevin Elwood MB BCh MRCP FRCP 3
}

T here is considerable evidence that both tuberculin skin tests (TSTs) and interferon-gamma release assays (IGRAs) are valid but imperfect for latent tuberculosis (TB) infection (LTBI). Neither test can distinguish LTBI from TB disease and, therefore, have no value for active TB detection (1). Both tests have suboptimal sensitivity in active TB, especially in HIV-infected persons and children $(2,3)$. Both tests appear to correlate well with gradient of exposure (3). While neither IGRAs nor the TST have high accuracy for predicting active TB, the use of IGRAs in some populations might reduce the number of people considered for preventive treatment (4).

However, there are key differences between the two tests (5). While the TST has high specificity in Bacille-Calmette-Guérin (BCG) unvaccinated persons, its specificity is lower and variable in those who have received BCG vaccination after infancy or have received multiple BCG vaccinations (6). In contrast, IGRA specificity remains high in BCG-vaccinated and unvaccinated populations (7). From a logistical perspective, IGRAs are more convenient for patients who do not have to return for the reading, and the laboratory readout is more objective than the subjective reading of TST induration. Finally, there is an important difference in terms of cost for the health care system - in general, IGRAs are more expensive to implement than the TST.

While many countries have published guidelines on IGRAs (8), the use of IGRAs for routine screening of health care workers (HCWs) remains an area of controversy. The 2005 United States Centers for Disease Control (CDC) guidelines on the QuantiFERON-TB Gold (QFT) assay (Cellestis, Australia) allowed for replacement of the TST with QFT for annual testing of HCWs in the United States (US) (9), and this was expanded to cover both commercial IGRAs in the 2010 update (10). In contrast, the Canadian guidelines on IGRAs have not recommended the use of IGRAs for serial testing of HCWs $(11,12)$.

While the performance of IGRAs in serial testing of HCWs was first reported six years ago (13), this topic has received significantly more attention in the past few years, culminating in a recent systematic review (14). In the current issue of the Canadian Respiratory Journal, Joshi et al (15) (pages 84-88) provide useful data on routine implementation of QFT for HCW screening in Arkansas (USA), where QFT replaced the TST in 2008. Joshi et al describe the challenges they faced in implementing the test and raise concerns about high rates of QFT positivity in a setting with very low historical TST conversion rates. They observed high reversion rates on repeat testing of positives and poor short-term reproducibility of positive QFT results. Based on their results, Joshi et al argue for the need for cautious interpretation of QFT results, especially those in the borderline zone around the cut-off.

The report by Joshi et al (15) is highly consistent with data that have emerged from many countries (16-25). Table 1 sumarizes the major serial testing studies of IGRAs in HCWs in low and intermediate
TB incidence settings (16-25), including the data from Arkansas (15), building on the systematic review by Zwerling et al (14). Overall, these data suggest that IGRA results vary greatly during serial testing. When simple negative/positive changes are used as cut-offs, IGRAs had high rates of conversions ( $2 \%$ to $15 \%$ ), which were frequently higher than the rates of TST conversions, and higher than the annual risk of TB infection expected in these low incidence settings. What is striking are the high rates of IGRA reversions - which range from approximately $20 \%$ to $40 \%$ in most studies.

Thus, while both TST and IGRAs are impacted by nonspecific variations, conversions and reversions during serial testing, IGRAs appear to have a very high frequency of conversions and reversions, and the consequences of such changes are unclear, posing challenges for implementation in routine occupational health programs. Indeed, a series of recent studies have described the challenges faced by US hospitals that switched to IGRA for HCW screening after the 2005 CDC guideline (15,17,25-28).

Despite the growing evidence base on IGRAs, there are several unresolved questions, especially in the context of serial testing (29). What cut-off should be used for IGRA conversion? We now know that a simple negative to positive definition is probably inappropriate and will result in a much higher conversion rate than what epidemiologically might be expected. This would then expose more HCWs to potentially unnecessary preventive therapy. Several studies have examined the within-person reproducibility of IGRA results over time, and many have proposed more stringent cut-offs based on reproducibility data, and proposals for a borderline zone of uncertainty have also been made (13,30-35). However, there is no consensus on the optimal cutoffs for conversions and reversions, and the need for a borderline zone for both IGRAs.

Should all those who are IGRA positive at baseline get retested routinely? Should IGRA positive results be repeated before recommending treatment? If yes, then what is the best approach for managing the anticipated reversions? Should those with IGRA reversions be carefully monitored but not given preventive therapy? What is the prognostic significance of IGRA reversions? Studies that have performed multiple time-point testing have shown diverse patterns of changes over time, and the prognosis of these phenotypes remains unclear (36), although there is evidence that both TST and IGRAs have suboptimal predictive value (4).

Regardless of the test used for serial testing, there is a need to reconsider the general strategy of annual testing of HCWs in North America, where TB incidence has declined to a very low level. Millions of HCWs undergo screening for LTBI every year, and a substantial proportion are low-risk employees who probably should not be screened at all. Arkansas is an excellent example, where the TB case rate was only 2.7 per 100,000 population in 2010 (37), which is reflected in the historical annual TST conversion rate of less than

${ }^{1}$ Respiratory Epidemiology $\mathcal{E}$ Clinical Research Unit, Montreal Chest Institute; ${ }^{2}$ Department of Epidemiology $\mathcal{E}$ Biostatistics, McGill University,

Montreal, Quebec; ${ }^{3}$ BC Centre for Disease Control $\mathcal{E}$ University of British Columbia, Vancouver, British Columbia

Correspondence: Dr Madhukar Pai, Departement of Epidemiology $\mathcal{B}$ Biostatistics, McGill University, 1020 Pine Avenue West, Montreal,

Quebec H3A 1A2. Telephone 514-398-5422, fax 514-398-4503, e-mail madhukar.pai@mcgill.ca 
TABLE 1

Serial testing studies of interferon-gamma release assays in health care workers (HCWs) in low and intermediate incidence countries

\begin{tabular}{|c|c|c|c|c|}
\hline \multirow[b]{2}{*}{ Author (reference), year, country } & \multirow[b]{2}{*}{ Duration between testing } & \multicolumn{2}{|c|}{ Conversion, n/N (\%) } & \multirow{2}{*}{$\begin{array}{c}\text { IGRA reversions*, } \\
\text { n/N (\%) }\end{array}$} \\
\hline & & Tuberculin skin test & IGRA* & \\
\hline Joshi et al (15), 2012, USA & 2 to 30 days & N/A & N/A & $18 / 45(40)$ \\
\hline Rafiza et al (16), 2012, Malaysia & 1 year & N/A & 69/703 (9.8) & $14 / 59(23.7)$ \\
\hline Fong et al (17), 2012, USA & $\begin{array}{l}1 \text { year or } 1 \text { to } 6 \text { months for repeat } \\
\text { of positive IGRA }\end{array}$ & N/A & $52 / 1857(2.8)$ & $8 / 10(80)^{\dagger}$ \\
\hline Torres Costa et al (18), 2011, Portugal & 1 year & $61 / 199(30.7)$ & $51 / 462$ (11) & \\
\hline Schablon et al (19), 2010, Germany & $\begin{array}{l}\text { High-risk HCWs tested annually, } \\
\text { all others evaluated every other } \\
\text { year }\end{array}$ & $\begin{array}{l}\text { Reversion rates: } \\
4 / 188 \text { (2.1) }\end{array}$ & $15 / 245(6.1)$ & $46 / 208(22.1)$ \\
\hline Ringshausen et al (20), 2010, Germany & 18 weeks & $\mathrm{N} / \mathrm{A}$ & 3/162 (1.9) & $13 / 42(32.6)$ \\
\hline Park et al (21), 2010, South Korea & 1 year & $\mathrm{N} / \mathrm{A}$ & $14 / 244(5.7)$ & 6/18 (33.3) \\
\hline Lee et al (22), 2009, South Korea & 1 year & $\mathrm{N} / \mathrm{A}$ & 21/146 (14.4) & N/A \\
\hline Chee et al (23), 2009, Singapore & 1 year & $16 / 75(21.3)$ & 9/182 (4.9) & N/A \\
\hline Yoshiyama et al (24), 2009, Japan & 2 and 4 years & $\begin{array}{l}\text { 0/18 (Note: denominator } \\
\text { includes only baseline } \\
\text { concordant positives) }\end{array}$ & $5 / 277(1.8)$ & N/A \\
\hline Pollock et al (25), 2008, USA & 1 to 7 months & N/A & $\begin{array}{l}\text { 2/43 (4.6). Selected HCWs } \\
\text { at 'increased risk' and } \\
\text { negative at baseline }\end{array}$ & $13 / 32(41)$ \\
\hline
\end{tabular}

${ }^{\star}$ All conversions/reversions using simple negative/positive; ${ }^{\dagger}$ Testing was performed among individuals with positive QuantiFERON-TB (Cellestis Ltd, Australia) results close to the cut-off point. IGRA Interferon-gamma release assay; N/A Not available

$0.1 \%$ among HCWs (15). Yet, more than 3000 employees at the Central Arkansas Veterans Healthcare System alone are expected to undergo LTBI screening every year. Not only does the current testing strategy pose obvious dilemmas in terms of who to treat, there are significant economic costs associated with occupational TB testing programs in North America.

In summary, routine implementation of IGRAs in serial testing programs poses challenges, especially when a test with poorly understood dynamic characteristics is deployed in a predominantly low-risk population. Current guidelines on the use of IGRAs do not adequately address these challenges, nor do they provide specific guidance on how to handle conversions, reversions and borderline results that fluctuate over time. With rapidly accumulating evidence from serial testing studies, existing IGRA guidelines will need to be

\section{REFERENCES}

1. Metcalfe JZ, Everett CK, Steingart KR, et al. Interferon-gamma release assays for active pulmonary tuberculosis diagnosis in adults in low- and middle-income countries: Systematic review and meta-analysis. J Infect Dis 2011;15;(Suppl 4):S1120-9.

2. Cattamanchi A, Smith R, Steingart KR, et al. Interferon-gamma release assays for the diagnosis of latent tuberculosis infection in HIV-infected individuals - a systematic review and meta-analysis. J Acquir Immune Defic Syndr 2011;56:230-38.

3. Mandalakas AM, Detjen AK, Hesseling AC, Benedetti A, Menzies D. Interferon-gamma release assays and childhood tuberculosis: Systematic review and meta-analysis. Int J Tuberc Lung Dis 2011;15:1018-32.

4. Rangaka MX, Wilkinson KA, Glynn JR, et al. Predictive value of interferon-gamma release assays for incident active tuberculosis: A systematic review and meta-analysis. Lancet Infect Dis 2012;12:45-55.

5. Pinto LM, Grenier J, Schumacher SG, Denkinger CM, Steingart KR, Pai M. Immunodiagnosis of tuberculosis: State of the art. Med Princ Pract 2012;21:4-13.

6. Farhat M, Greenaway C, Pai M, Menzies D. False-positive tuberculin skin tests: What is the absolute effect of BCG and nontuberculous mycobacteria? Int J Tuberc Lung Dis 2006;10:1192-204.

7. Pai M, Zwerling A, Menzies D. Systematic review: T-cell-based assays for the diagnosis of latent tuberculosis infection: An update. Ann Intern Med 2008;149:177-84. updated with specific recommendations on interpretation of serial testing results. Until such time, infection control and occupational health programs must be cautious in interpreting serial testing results, and consider the magnitude of change in interferon-gamma responses, and not rely on simplistic cut-offs. As is always the case, it is particularly important to consider clinical context, TST results, if available, and history of exposure in making decisions about preventive therapy. Using an IGRA result alone will not suffice.

ACKNOWLEDGEMENTS: The authors are grateful to Alice Zwerling, McGill University, Montreal, for technical assistance and helpful review of the manuscript.

8. Denkinger CM, Dheda K, Pai M. Guidelines on interferon-gamma release assays for tuberculosis infection: Concordance, discordance or confusion? Clin Microbiol Infect 2011;17:806-14.

9. Mazurek GH, Jereb J, Lobue P, Iademarco MF, Metchock B, Vernon A. Guidelines for using the QuantiFERON-TB Gold test for detecting Mycobacterium tuberculosis infection, United States. MMWR Recomm Rep 2005;54(RR-15):49-55.

10. Mazurek M, Jereb J, Vernon A, LoBue P, Goldberg S, Castro K. Updated guidelines for using interferon gamma release assays to detect Mycobacterium tuberculosis infection - United States, 2010. MMWR Recomm Rep 2010;59:1-25.

11. Canadian Tuberculosis Committee. Updated recommendations on interferon gamma release assays for latent tuberculosis infection Can Commun Dis Rep 2008;34:1-13.

12. Canadian Tuberculosis Committee. Recommendations on interferon gamma release assays for the diagnosis of latent tuberculosis infection - 2010 Update. Can Commun Dis Rep 2010;36:1-21.

13. Pai M, Joshi R, Dogra S, et al. Serial testing of health care workers for tuberculosis using interferon-gamma assay. Am J Respir Crit Care Med 2006;174:349-55.

14. Zwerling A, van den Hof S, Scholten J, Cobelens F, Menzies D, Pai M. Interferon-gamma release assays for tuberculosis screening of healthcare workers: A systematic review. Thorax 2012;67:62-70.

15. Joshi M, Monson TP, Woods GL. Use of interferon-gamma release assays in a health care worker screening program: Experience from a tertiary care centre in the United States. Can Respir J 2012;19:84-8. 
16. Rafiza S, Rampal KG. Serial testing of Malaysian health care workers with QuantiFERON(R)-TB Gold In-Tube. Int J Tuberc Lung Dis 2012;16:163-8.

17. Fong KS, Tomford JW, Teixeira L, et al. Challenges of interferongamma release assay conversions in serial testing of health care workers in a tuberculosis control program. Chest 2012, January 19 (E-pub ahead of print).

18. Torres Costa J, Silva R, Sa R, Cardoso MJ, Nienhaus A. Serial testing with the interferon-gamma release assay in Portuguese healthcare workers. Int Arch Occup Environ Health 2011;84:461-9.

19. Schablon A, Harling M, Diel R, Ringshausen FC, Torres Costa J, Nienhaus A. Serial testing with an interferon-gamma release assay in German healthcare workers. GMS Krankenhhyg Interdiszip 2010;5(2).pii: Doc05.

20. Ringshausen FC, Nienhaus A, Schablon A, Schlosser S, Schultze-Werninghaus G, Rohde G. Predictors of persistently positive Mycobacterium tuberculosis-specific interferon-gamma responses in the serial testing of health care workers. BMC Infect Dis 2010;10:220.

21. Park HY, Jeon K, Suh GY, et al. Interferon-gamma release assay for tuberculosis screening of healthcare workers at a Korean tertiary hospital. Scand J Infect Dis 2010;42:943-5.

22. Lee K, Han MK, Choi HR, et al. Annual incidence of latent tuberculosis infection among newly employed nurses at a tertiary care university hospital. Infect Control Hosp Epidemiol 2009;30:1218-22.

23. Chee CB, Lim LK, Barkham TM, et al. Use of a T cell interferongamma release assay to evaluate tuberculosis risk in newly qualified physicians in Singapore healthcare institutions. Infect Control Hosp Epidemiol 2009;30:870-5.

24. Yoshiyama T, Harada N, Higuchi K, Nakajima Y, Ogata H. Estimation of incidence of tuberculosis infection in health-care workers using repeated interferon-gamma assays. Epidemiol Infect 2009;11:1-8.

25. Pollock NR, Campos-Neto A, Kashino S, . Discordant QuantiFERON-TB Gold test results among US healthcare workers with increased risk of latent tuberculosis infection: A problem or solution? Infect Control Hosp Epidemiol 2008;29:878-86.
26. Gandra S, Scott WS, Somaraju V, Wang H, Wilton S, Feigenbaum M. Questionable effectiveness of the QuantiFERON-TB Gold Test (Cellestis) as a screening tool in healthcare workers. Infect Control Hosp Epidemiol 2010;31:1279-85.

27. Schneider WJ, Brown AE, Eisenstein C. QuantiFERON-TB testing for latent tuberculosis infection in low-prevalence countries: Making the most of an imperfect process. Infect Control Hosp Epidemiol 2011;32:1055.

28. Herrera V, Perry S, Parsonnet J, Banaei N. Clinical application and limitations of interferon-gamma release assays for the diagnosis of latent tuberculosis infection. Clin Infect Dis 2011;52:1031-7.

29. Pai M, O'Brien R. Serial testing for tuberculosis: can we make sense of T cell assay conversions and reversions? PLoS Med 2007;4:e208.

30. van Zyl-Smit RN, Pai M, Peprah K, et al. Within-subject variability and boosting of T-cell interferon-gamma responses after tuberculin skin testing. Am J Respir Crit Care Med 2009;180:49-58.

31. van Zyl-Smit RN, Zwerling A, Dheda K, Pai M. Within-subject variability of interferon-g assay results for tuberculosis and boosting effect of tuberculin skin testing: A systematic review. PLoS One 2009;4:e8517.

32. Veerapathran A, Joshi R, Goswami K, et al. T-cell assays for tuberculosis infection: Deriving cut-offs for conversions using reproducibility data. PLoS One 2008;3:e1850.

33. Ringshausen FC, Nienhaus A, Torres Costa J, et al. Within-subject variability of Mycobacterium tuberculosis-specific gamma interferon responses in German health care workers. Clin Vaccine Immunol 2011;18:1176-82.

34. Perry S, Sanchez L, Yang S, Agarwal Z, Hurst P, Parsonnet J. Reproducibility of QuantiFERON-TB gold in-tube assay. Clin Vaccine Immunol 2008;15:425-32.

35. Doberne D, Gaur RL, Banaei N. Preanalytical delay reduces sensitivity of QuantiFERON-TB gold in-tube assay for detection of latent tuberculosis infection. J Clin Microbiol 2011;49:3061-4.

36. Pai M. Spectrum of latent tuberculosis - existing tests cannot resolve the underlying phenotypes. Nature Rev Microbiol 2010;8:242-43.

37. Centers for Disease Control and Prevention. Reported Tuberculosis in the United States, 2010. U.S. Department of Health and Human Services. Atlanta, 2011. 


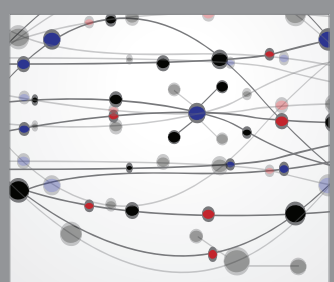

The Scientific World Journal
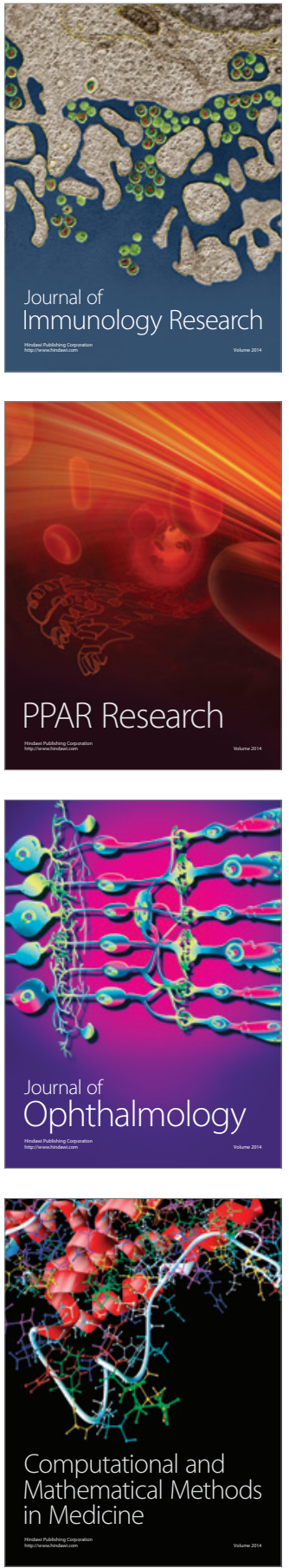

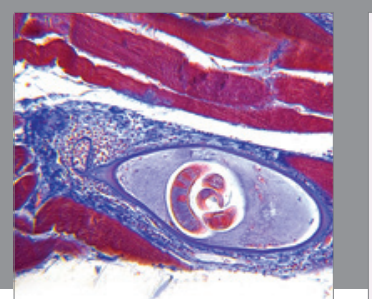

Gastroenterology Research and Practice

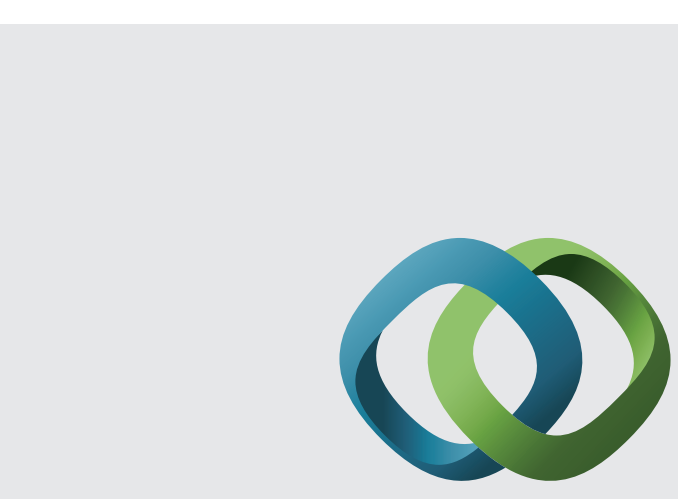

\section{Hindawi}

Submit your manuscripts at

http://www.hindawi.com
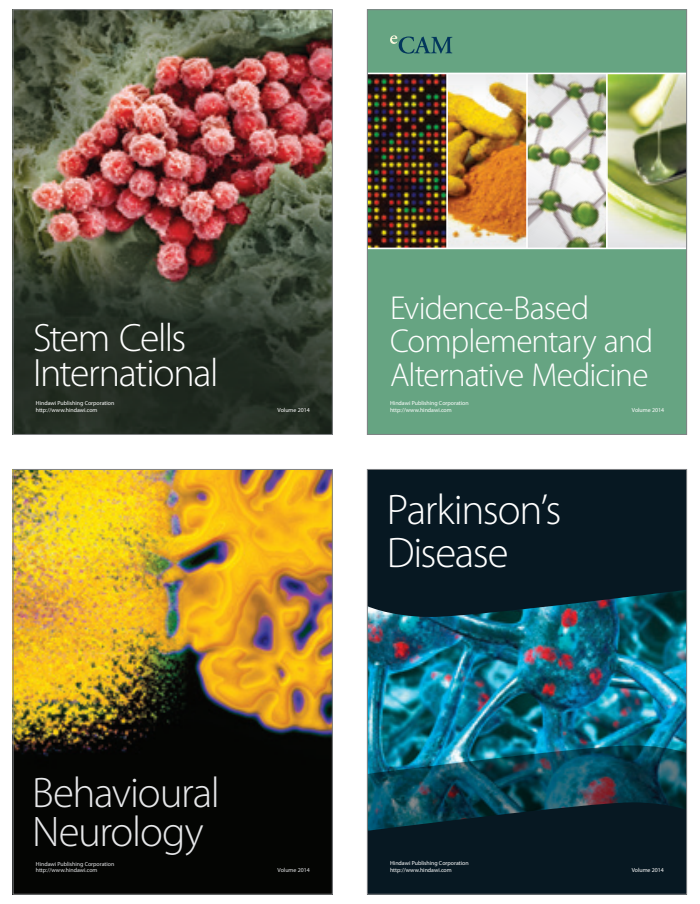
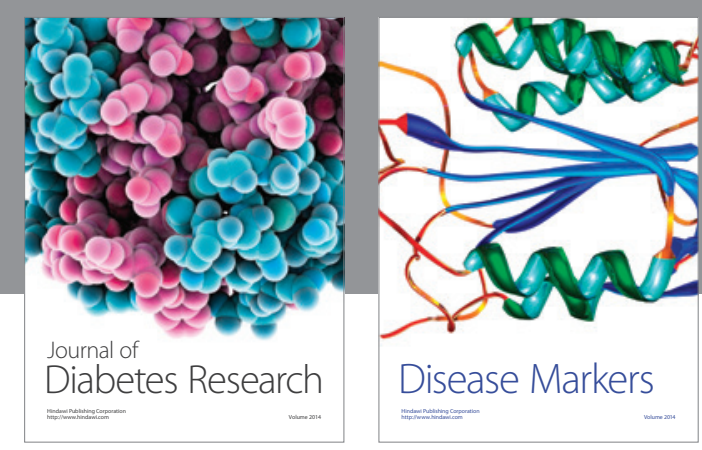

Disease Markers
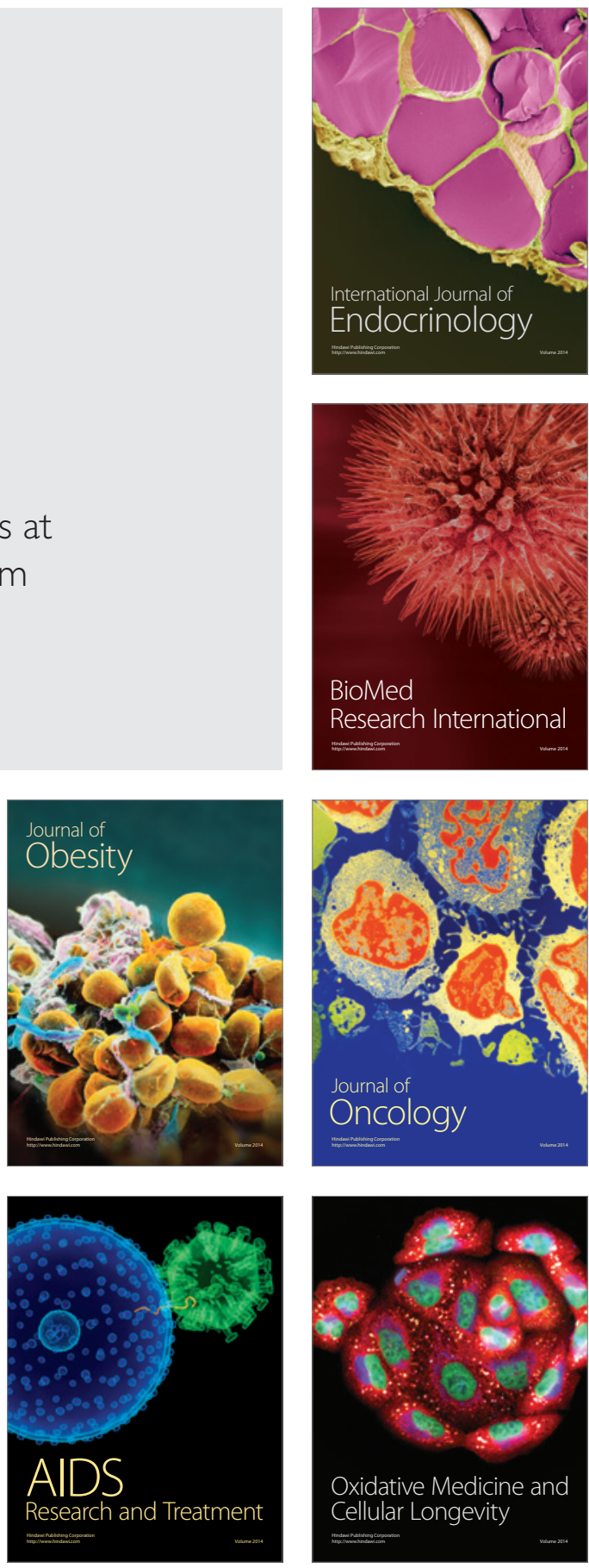